\title{
Optimize The Placement Of Print Advertisement And Signage By Anamorphic Illusion
}

\author{
Ho Jie Lin \\ School of the Arts, \\ Universiti Sains Malaysia \\ Penang, Malaysia \\ jielin1104@gmail.com
}

\author{
Mohammad Khizal Saat \\ School of the Arts, \\ Universiti Sains Malaysia \\ Penang, Malaysia \\ mkhizal@usm.my
}

\author{
Tetriana Ahmad Fauzi \\ School of the Arts, \\ Universiti Sains Malaysia \\ Penang, Malaysia \\ tetriana af@yahoo.com
}

\begin{abstract}
Print advertisement is a mean to communicate about products, services or ideas which is intended to inform or influence people who received the message that is usually persuasive by nature and paid by the related sponsors. Strategic placement of advertisement and signage is one of the crucial key of effective communication. Brand recognition can be built through a well designed advertising which is strategically placed. A well develop media placement plan can save marketer from unnecessary and wasteful spending. Placement of advertisement and signage is often constrained by the space and structure of place or location. Visual placement is referring to the place in which a message is portrayed and displayed. The limitation includes the structure of building, the size and space of the placement and the viewing perspective of viewers. This research aimed to study anamorphic illusion as a new creative visual language to deliver message in advertisement to the audience. It also explored the relationship between the laws of perspective and the message portraying tactics and styles. With the analysis of the above study, it will develop a new artistic technique to optimize the visibility of message by overcoming the limitation of visual placement. Through the method of studio practice this study mainly focuses on using law of perspective in creating anamorphic art as the solution to overcome the constraint space and structure in portraying the message in advertisement to the audience. The research was carried out with exploration, interpretation and manipulation through mock-up model. Mock-up of the structure and space will be built in order to secure the idea and concept of perspective study and visual perception of audience which can help in the application of the real artwork. Limitation of structure and space of the location for the placement of print advertisements and signage were recorded in sketches and photographs as the collection of data. This research can give an in-depth study on implication of Anamorphic illusion in optimising the placement of print advertisement and signage. This study also provides a suggestion on new creative opportunity and evaluation in placing the message toward audience.
\end{abstract}

Keywords : Advertisement, anamorphic, studio practice.

\section{INTRODUCTION (RESEARCH BACKGROUND)}

This research is aimed to study anamorphic illusion as a new creative visual language to deliver message to the audience. This study also explores the relationship between the laws of perspective and the message portraying tactics and styles. With the analysis of above study, it will develop a new artistic technique to optimize the visibility of message by overcoming the limitation of visual placement. Visual placement is referring to the place which message was portrayed and displayed, the limitation included the structure of building, the size and space of the placement and the viewing perspective of viewer. Extensive research over the years has supported the limitation as mentioned have influence toward the effectiveness of message (Jin K. Han, 1992; Siddiqui et al., 2016). Thus, this studio research will primarily emphasize on experimenting the message portraying tactics and styles on different type of structure. All the information and data such as literature review, image references, discussion or interview which have gained in this study will be processed and executed in the form of artwork.

In twenty-first century each individual belongs to a global society and the news of latest happenings spread throughout the world within short time and the amount of information continues to grow at an ever-increasing rate (Kellner \& Share, 2007). Research claim people are deluged with around 100,500 words a day which equivalent to 23 words per second, through various of source such as internet, television, advertisement and etc (Bohn, R \& Short, J., 2012). Furthermore, in this media saturated world caused people do not respond to information surround them especially the millennial generation (Newman, 2015). This phenomenon results in, barriers to effective communication which created threads to different industries or organisation.

Visual communication is a broad spectrum that includes all kind of visual design which included signage and advertisement. The power of images in modern communication is irrefutable, this can be proved in the world of social media which visual content is 40 times more likely to get shared than those with text alone (Lee, K., 2014). Humans are visual creature which half of the brain is directly or indirectly devoted to processing visual information (Trafton, A., 2014). Research also proven that $65 \%$ of people are visual learner, the best way to drive message to their memory is through visual (Bradford, W.C., 2004).

This research will focus on using typography as a medium to deliver message because it is the most common and irreplaceable graphical communication elements in visual design (Nakilcioğlu, I.H., 2013). Typography is the visual art of creating words and serves as a tool to imbues a message with visual meaning to express particular emotions and feeling to audience through the application of semiotic theory. According to a typographer Robert Bringhurt: "Typography exists to honour content". Besides, it had an important role in building visual hierarchies which is arrangement of information in a way that implies important, and in commercial design to create brand identity (Ho, A.G, n.d.). In this research advertise message with a central 
focus of public welfare rather than selling a product or a service.

The starting of Anamorphosis technique in the history of art is nearly simultaneous with the invention of linear perspective (Collins, D., 1992). This technique was first explored by Leonardo Da Vinci who drawn Anamorphic drawing of a child's head (Figure 1) in his note book dating from the 1480s. There were two types of Anamorphosis which termed as "oblique" and "catoptric". The "oblique" form of Anamorphic art (Figure 2) also known as perspective Anamorphosis. Next, the "catoptric" form of Anamorphosis art (Figure 3) also known as mirror Anamorphosis. This type of Anamorphic art only can be seen reflect in a typical mirror shape like cylindrical, conical and pyramidal. Both of the Anamorphic illusion gets a spatial illusion of two-dimensional (2D) image.

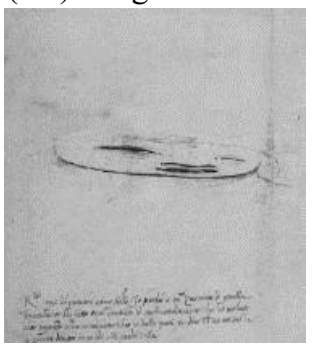

Figure 1. Leonard da Vinci, Anamorphosis of a child's face

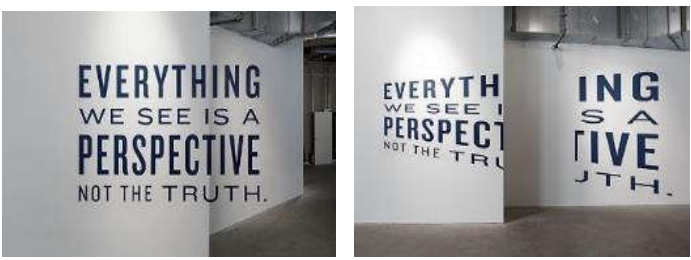

Figure 2. Example of "Oblique" illusion by Thomas Quinn.

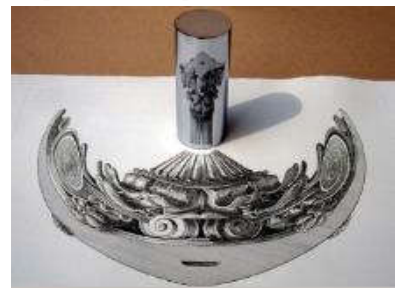

Figure 3. Example of "Catoptric" illusion by István Orosz.

This studio research will produce artworks which involve the theory and concept of visual communication, typography, and anamorphic illusion. The objective of this study is anamorphic illusion will be developed as artistic technique to overcome the limitation of portraying and optimize the message to audience.

\section{PROJECT OUTLINE}

This study will conduct in methodology of studio practice in order to achieve high quality artworks. The research will start with investigating the topic by analysing, synthesising and interpreting information and data from literature review. The literature review included the theory and concept of visual communication, typography, graffiti and anamorphic illusion. Apart from that, this research also involved study of previous artworks which done by artist or designer with application anamorphic illusion in their works. This studio research primarily emphasizes on experimenting the message portraying technique on different type of structure through anamorphic illusion. Observational study through online and on-site regarding the structure of visual placement will be carried out and recorded in sketches or photographs as the collection of data. The research will be carried out with exploration, interpretation and manipulation through mock-up model. Mock-up of the structure and space will be built in order to secure the idea and concept of perspective study and visual perception of audience which can help in the application of the real artwork. The final artworks will be executed using digital printing stick on build structure as installation artwork.

\section{Research Objective}

1. To study anamorphic illusion as a new creative visual language to deliver message in advertisement to the audience.

2. To explores the relationship between the laws of perspective and the message portraying tactics and styles.

3. To develop a new artistic technique to optimize the visibility of message by overcoming the limitation of visual placement.

\section{Research Question}

1. How to transform anamorphic illusion as a new creative visual language to deliver message in advertisement to the audience.

2. What is the relationship between the laws of perspective and the message portraying tactics and styles.

3. How anamorphic illusion help to optimize the visibility of message by overcoming the limitation of visual placement.

\section{RESEARCH SIGNIFICANCE}

The significance of the research is based on the aspect of manipulating and integrating the concept of Anamorphic illusion. The data collection will bring benefit and reference to artist, designer, art student in doing related optical illusion art project. Besides that, the artwork of the research tent to give new experiences toward the merging of visual art and math calculation. As a new creative way to optimise the placement of message by overcoming the limitation of the visual placement in structure and space. Message portraying method will influence the effectiveness of message communication toward the audience. The research practice to step beyond ordinary artwork production of visual communication. In the past, many research have be carried out regarding the element of visual communication but there is no adequate amount of research regarding the portraying technique of message. This study will provide a source of reference and inspiration to enrich the effectiveness of visual communication through experimenting the portraying technique with anamorphic illusion. Besides that, this research will give an in-depth study of message displaying technique which is not purely placing message on flat surface but raise the effectiveness of 
message to more "dynamic" and "interactive" with the surrounding and the audience. Previously, the anamorphic art always been practiced by artist and the artwork was display in gallery or museum. This research will go beyond the tradition by merging the commercial with mass production technique into gallery-based design practice. This study hopes to inspire more artist and designer to practice and experiment the optical illusion technique in commercial industrial.

The research investigation also significance in contributing toward the commercial industries and organisations by introduce new approach of displaying message to the audiences. Placement of message often constraint by the space and the structure of the location. Thus, designers have to consider the constrain of surrounding and adjust the size of the message in order to fit space, which simultaneously will influence the readability and impact of the message. Next, the designed message usually portrayed in single planner surface which is not eye catching, Anarmorphosis allow message to portray in multiple planner surface and go beyond the tradition message portraying technique. In this information clutter era, Anamorphosis help in creating more memorable impression message to the audience because of interactive between message and audience eye. This interaction causes the message retain in their mind longer and allow them to recall the message easily due to the interesting approach. Therefore, this research will provide a new evaluation for advertiser and marketer toward the message placement approach.

\section{THE CONTEXT RELATED ART PRACTICES: TYPOGRAPHY THROUGH ANAMORPHIC OPTICAL ILLUSION}

Anamorphic illusion is a type of mind bending optical illusion which involved the visual perception of audience and based on precise mathematical and physical rule. The term of anamorphic is derive from Greek "ana" (again) and "morphe" (form). Anamorphosis which has the meaning of "transformation" or "reformation", it was first used in Magia Universails in 1657 by the German Jesuit scholar Gaspar Schott. Anamorphosis is an art of distorted projection which obey the laws of perspective that was developed during the Renaissance. In order to bring the image back to the normal way, it requires audience to view it in special way. According to Webster's 1913 Dictionary:

\footnotetext{
"A distorted or monstrous projection or representation of an image on a plane or curved surface, which, when viewed from a certain point, or as reflected from a curved mirror or through a polyhedron, appears regular and in proportion; a deformation of an image."
}

According to the book of Basice Design 03: Typograph definition for typography is:

\footnotetext{
"Individual letters, when arranged in a particular way, represent the sound of a spoken language
}

and visually express ideas in such a way that another person can understand them in the manner intended".

Typography is the visual art of creating words, it not only serves as a conduit of verbal narrative. According to Eric Gill a typographer: "Letters are things, they are not picture of things". It also imbues a message with visual meaning to express particular emotions and feeling to audience (Ho, A.G., 2013). Since visual communication is a way of deliver message to audience through sight it can be incorporate with the technique of optical illusion. Optical illusion is a trick on brains into seeing things which may or may not be real (Seckel, 2006). Furthermore, through the semiotic theories able to extended, develops and give more insight toward the message of artworks (Najafi, F. \& Abbas, M., 2007).

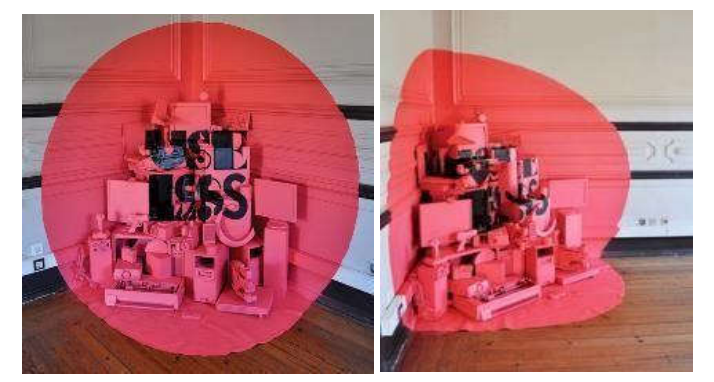

Figure 5. Akacorleone, Useless. 2011, Mix media 250 x $250 \mathrm{~cm}$.

Akacorleone his real name is Pedro Campiche born in 1985, he is a visual artist of Portuguese and Swiss descent. He started out as a graffiti writer in the underworld of his native Lisbon. The anamorphic installation (Figure 5) produced by Akacorleone in year 2011 , illustrated the idea of accelerating development of technology. It is a site-specific installation created for Experimental Design Festival. Artist used the technological object such as monitor, typewriter, CPU, speaker and etc as the material of installation by stacking it up randomly at the corner of the room.

Artist display the word of "useless" through the technique of anamorphic optical illusion. Looking at the installation from a different angle only allow audience to see partly of the text. However, the text will be appeared clearly from a specific angle. In order to enhance the visibility of the word artist painted the background with pink. Anamorphosis able to make simple typography almost magically appear out of thin air. The installation conveys the message of today tech obsess society caused the technological object obsolete almost instantly. Through this method and material of presentation able audience to engage with electronical waste (E-waste) problem. This show that with wisely use of the material and structure will enhance the meaning of message and will be impactful to the audience. 


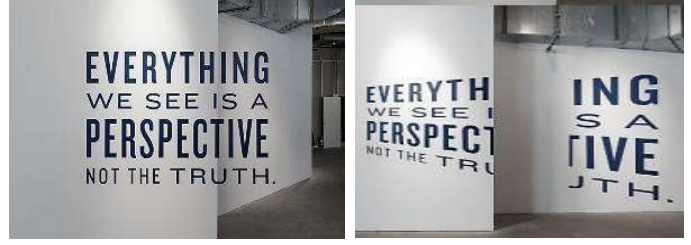

Figure 6. Akacorleone, Everything we see is a perspective not the truth. 2013, Mural on wall.

Thomas Quinn is a graphic designer from Chicago Illinois he created this inspiring anamorphic type piece. The designer uses many different types of art to create illustrations and typographics in simplistic yet smart ways, Figure 6 is one of the examples of his work. Looking at the artwork above it would look almost normal at first glance but seemingly like it couldn't exist within the 3D space it inhabits. Thomas Quinn uses perspective Anamorphosis to make simple typography appear on 3D space, looking at the image from a different angle you can clearly see how the typography was painted onto the walls in skewed. While standing in a perfect set from an angle the text will be appear perfectly. Besides that, artist also used the structure of the wall to enhance the meaning of the take by ties it to a larger point about seeing situations from another perspectives.

\section{STUDIO INVESTIGATION AND FINDINGS}

The human eye is an organ which is predominately use to experience and understand the world around us. This recognition of vision's unique power has led to the development of visual communication (Few, S., 2006). It has become one of the most important approach in communicate and share information (Kohok, R., 2018). To experience visual communication, it is not necessary for us to visit and art museum or gallery. Packaging, signs, logos, poster, advertisement and etc are the example of visual communication. All these come with a message in a beautiful way and more impressive than the text alone.

The process began with information gathered by the sight and processed by the brain, creating a perception that make sense of the world around us. Many researches showed that the limitation of building structure, size and space of the placement and the viewing perspective of viewer influence the effectiveness of message (Jin K. Han, 1992; Siddiqui et al., 2016). This studio research will produce artworks which involve the theory and concept of anamorphic illusion, visual communication, typography and semiotic. The theories and concept mention above will give an in-depth support toward the artworks that will be produce at the end of the study. Research will start with investigating the topic by analysing, synthesising and interpreting information and data from literature review

Prior to the creation of the final research study, a preliminary study of the anamorphic illusion on different structures has been carry out. This study was executed in order to confirm the practicable execution of the Anamorphic optical illusion in different form of structure. In the study, it begins with sketches of structure with different design of form and shape (Figure 7), these sketches symbolise the structure and location of building which the message will be portrayed. The idea of sketches is gain through observation study through online images and onsite buildings. Nine different sketches were chosen and built as the mock-up structure of building which image will be portray on it. The material used in building the mock-up are cardboard and paper (Figure 8). The size of each mock-up is approximately $200 \mathrm{~mm} \times 250 \mathrm{~mm}$.

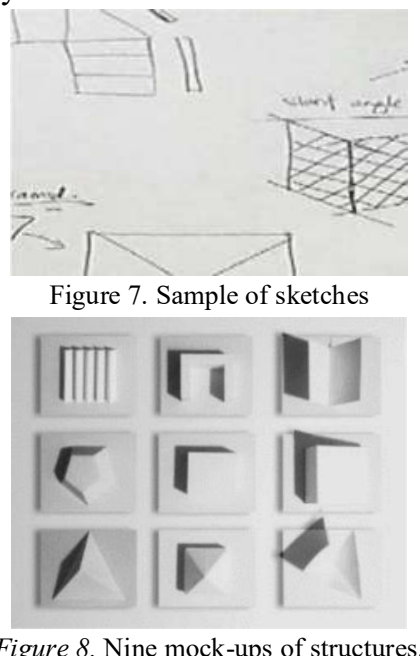

Visual images that used in this artwork is related to signages, celebration quote and advertisement of goods. Since this is the initial study to prove the practicality of the idea, the source of visual images was taken from online free image website. The images were carefully edit and calculate according to the perspective of viewing. These visual images were executed using printer and stick on the mock-up structure. (Figure 9) show the sample of the image portray on the structure on the right and normal visual image on the left. The result study (Figure 10) of the preliminary study proved Anamorphic illusion allow image to portray on extrude and bevel structure. However, in order to see the image accurately it requires audience to obey the rule of Anamorphic illusion. Which audience have to view images with the right angle and distance.
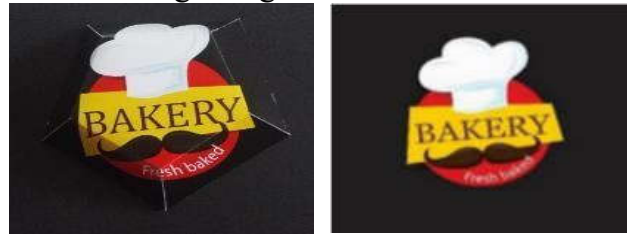

Figure 9. Sample result for preliminary study.
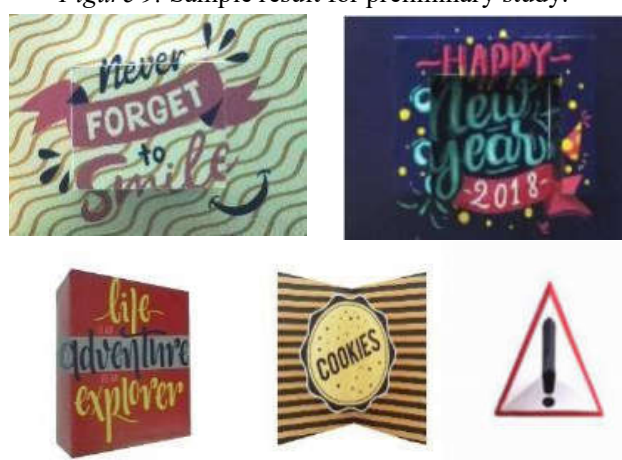

Figure 10. Examples of result study for preliminary study.

The emphasis of the artwork is on discovering the artistic technique of Anamorphic illusion to overcome 
the constraints of structure in portraying message to audience. Print advertisement and signage was chosen as the subject of the message in this initial study of anamorphic optical illusion. Print advertisement and signage are one of the oldest and continue to be one of the most effective forms of advertising on the market. Mass advertising media such as TV, radio broadcast and internet pop-out it can be switch off by audience. Unlike, print advertisement and signage such as billboard, banner and signage of business is always there to be view by audience. The print advertisement and signage were more cost-effective compare to mass advertising. Thus, it can be afforded by small enterprise. The final artworks of this research are about the exploration of using Anamorphic optical illusion to deliver the message portraying tactics or styles to enhance effective visual communication.

The process of making the final artworks began with the observation of the structure of building in order to have an indepth understanding of the limitation and the visual placement of signage and advertisement. The limitation or the obstacle for audience to view advertisement or signage was recorded such as the pillar, size, structure of the building and etc. Moreover, majority of the advertiser or marketer only display the advertisement or signage on flat surface. This portrays that new visual tactic to present message to audience is absolutely needed. With the data gain from the observation study sketches of mockup was produces, to envision the limitation and the obstacle of visual placement. Mock-up was designed in geometric shape because geometry was the basic form of building.
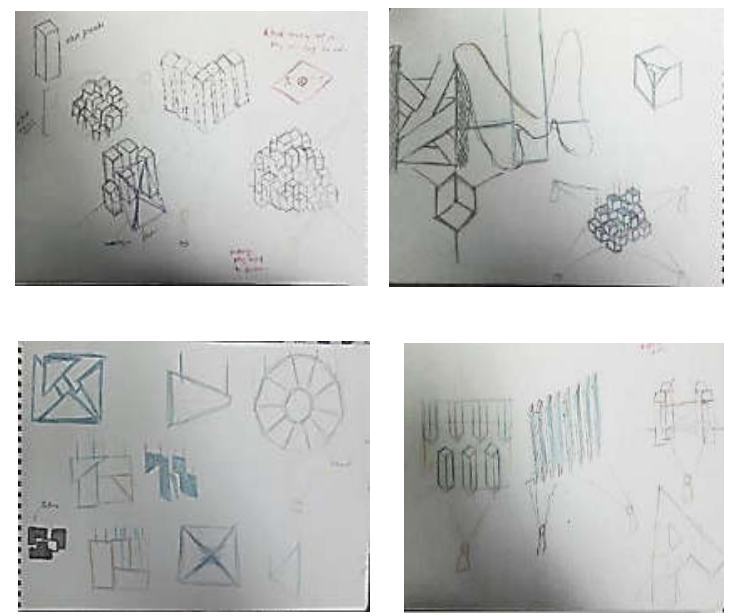

Figure 11. Examples of mock-up sketches.

Some of sketches was selected and build into small mock up (Figure 12) to identify the potential problem involving with size and the material use for final artworks. After studying of the mock-up, the decision of making three different eye level structure for final installation was decided. Which are viewing the artwork with high angle perspective, eye level and low angle perspective. Before the creation of the final design model, sketches (Figure 13) were produced in order to visualize the outcome. Besides that, 3D modelling of the sketches was also created in order to secure the final outlook of the installation. The research study continues with building up the structure of the installation with modelling board as the main material (Figure 14).

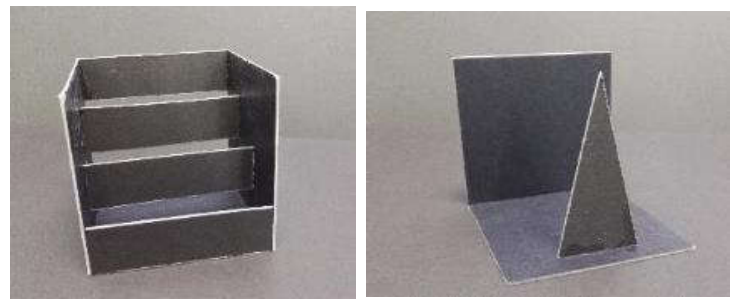

Figure 12. Examples of mock-up.

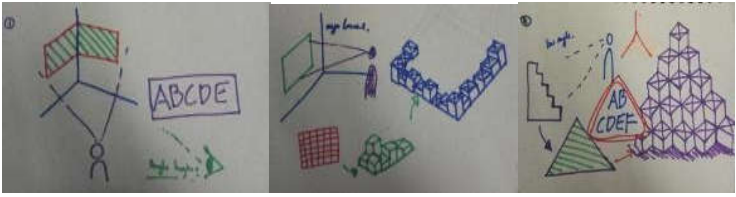

Figure 13 Three types of eyes levels -High angle perspective, Eye level perspective and Low angle perspective. Sketches of final artworks.

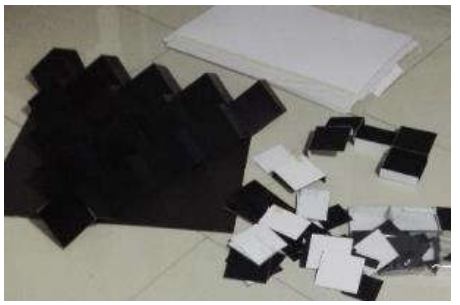

Figure 14. Progress of making the installation structure.

\section{First Artwork: Help Me (2018)}

The first artwork was based on the corner structure of building which normally advertiser and marketer do not place advertisement or signage. This study would like to introduce and utilized the two-plane corner structure to portray message to audience. Through the help of anamorphic optical illusion, it could create a 3D pop out effect toward audience. The process of making the artwork start with designing the text using Adobe Illustrator (Figure 15). The design of type starts by experimenting the colour and the composition. The artwork design used the text of "Help Me" experimentation with random text for the sake of experiment only and it is a powerful word which can capture people attention easily.

Furthermore, Adobe Photoshop was used to fine tune the effect of the design to make it more 3D by adding shadow and lighting. The process continues with analysing of design artwork into structure through Anamorphic optical illusion. This is to identify the final measurement of structure and form of building which involving size and the perspective of viewing. This a crucial step which formation of anamorphic optical illusion obey the rule of perspective.

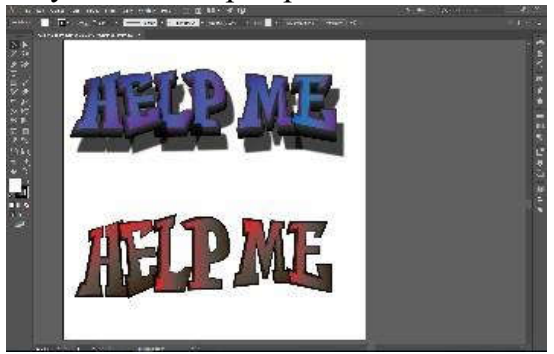

Figure 15. Design studies using Adobe Illustrator. 
The 3D sketch (Figure 16) of structure and form of building was drawn using Paint $3 D$ to foresee the final result. The calculation of size measurement and perspective angle according to rule of anamorphic illusion. After the calculation, the design is resized and edited in Adobe Photoshop. The design was executed in print using the material of sticker. This technique allows to execute in mass volume which is important for advertiser and marketers to deliver message toward their audience.

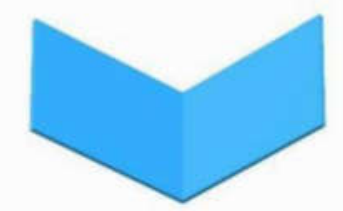

Figure 16. 3D sketch of structure

The final installation (Figure 17) outcome consists of simple typography design text with extraordinary effect. With the help of Anamorphic optical illusion, it creates a floating and pop out effect for the text. Looking at the image from a different angle the text will be skewed and distorted (Figure 18) but if the audience stand in a perfect position the text will appear perfectly for them to view. This tactic of portraying stands out from the others and able to retain longer in the mind of audience. Besides that, this artwork was presented in the corner structure of the building which always been neglected by the advertiser and marketers. Through this artwork and the technical capability of Anamorphic optical illusion created a new creative message portraying technique to the audience.

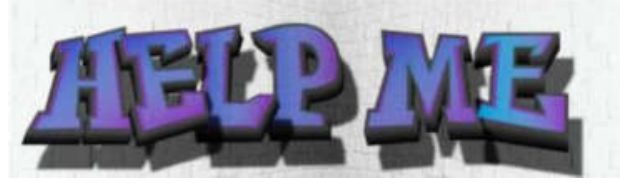

Figure 17. Picture of First installation "Help Me" (2018)
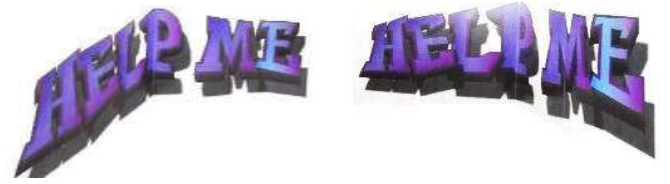

Figure 17. Picture of First installation "Help Me" (2018)

\section{Second Artwork: I'm Fine; Save Me (2018)}

The second artwork was created with the basis of viewing Anamorphic optical illusion art structure with eyelevel perspective. The artwork begins with experimenting typography in a way with the possibility of conveying two meaning type design. The text "I'm fine; Save Me" was used because it allows more interaction with audience which will create surprise to them. The text was design and draw in Adobe Illustrator (Figure 19). The finishing of the typography design (Figure 20) was enhanced in Adobe photoshop by adding the special effect like 3D, texture and shadow.

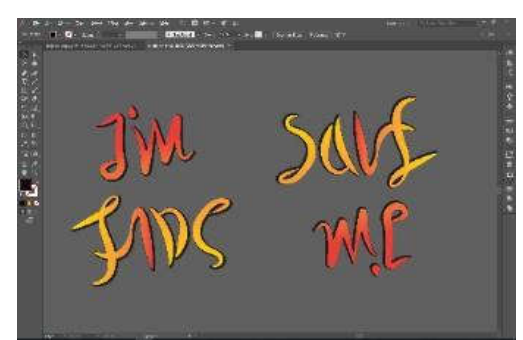

Figure 19. Design studies using Adobe Illustrator.

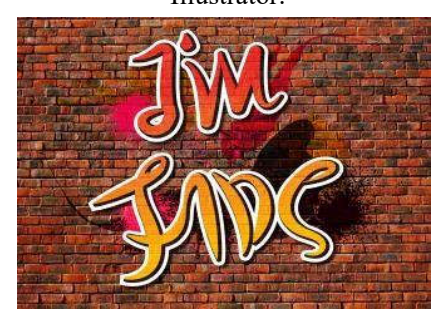

Figure 20. The manipulation of typography using Adobe Photoshop

This design is portrayed on a complicated design structure compare to first artwork, in order to test the visibility and readability of message through Anamorphic optical illusion. On the other hand, is to examine the validity of anamorphic optical illusion to overcome the limitation of visual placement. The structure is design as the following (Figure $21 \&$ Figure 22 ), design process continues with analysing of design artwork into structure through anamorphic optical illusion. This is to identify the size artwork and the perspective angle of viewing. The process of calculation and editing was carried out with Adobe Photoshop. The execution method is similar with the first artwork which print on sticker.

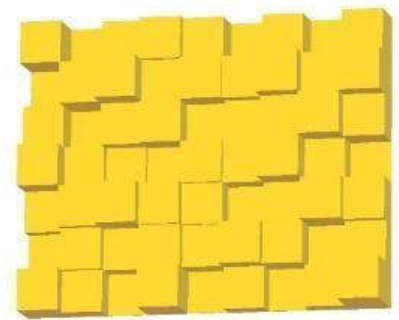

Figure 21. 3D sketch of second artwork

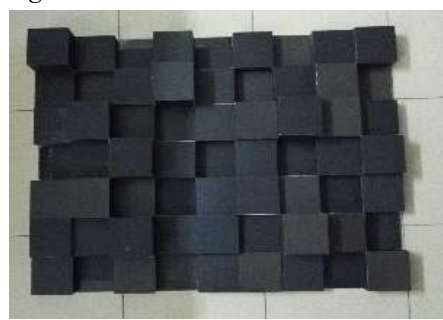

Figure 22. structure of second artwork

The final artwork of second installation (Figure 23) require audience to spend some time to figure out the text of "I'm Fine" and "Save Me". In the beginning audience will only find out the text of "I'm Fine", when the audience view the installation from opposite direction the second text will appear in the installation which is "Save Me". This study shows that through Anamorphic optical illusion it can overcome the limitation of visual placement successfully in the term of size, structure and distance. Moreover, through Anamorphic optical illusion the message will only appear when people view 
the installation in a correct perspective and distance. When the audience view it in different angle (Figure 24) it only appears part of the design, in such way it creates curiously and lead them to discover the message. This anamorphic installation provides more interactive interaction compare to previous artist work by allowing two way of viewing.
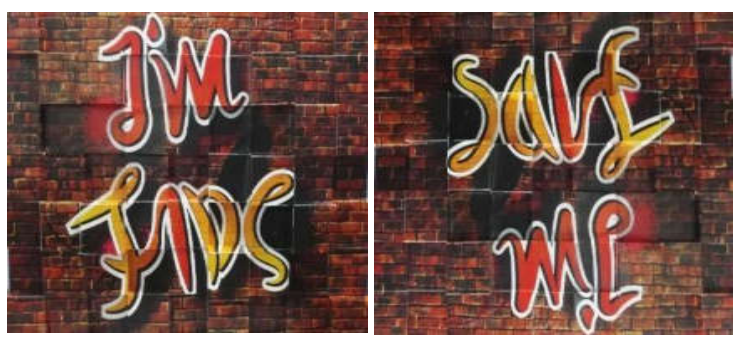

Figure 23. Picture of Second Artwork: I'm Fine; Save Me (2018)
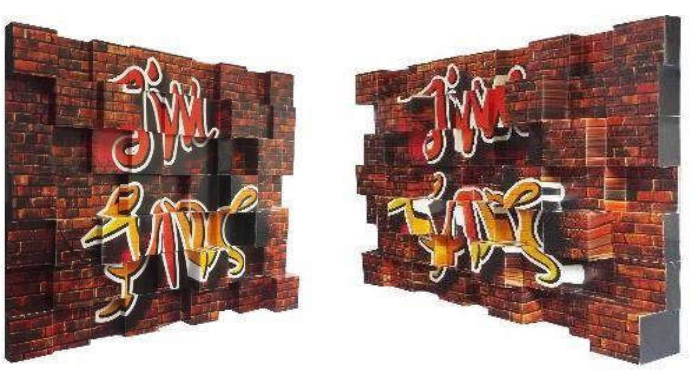

Figure 24. Picture of different angle for I 'am Fine: Save Me (2018)

\section{Third Artwork: I Feel Miserable (2018)}

The objective of third artwork pertains to experiment with viewing the Anamorphic artwork with low angle perspective. This ideal is generated from the observational study of building structure. Nowadays people always look on phone while walking and this trend affected how people look, research study proved this group of people were more caution toward things below their eye level (Timmis, et al.,2017). Moreover, it is also hard to found message display on the lower corner of the building. This study aimed to create new creative visual language to deliver message in advertisement to the audience with the corner of the building.

This study starts with creating mock-up design that suit with the corner structure. Therefore, the structure of pyramid was designed to be placed in the lower corner of the building (Figure $25 \&$ Figure 26). After building up of the structure, the study continues with the design of text using Adobe Illustrator and enhance the design effect with Adobe Photoshop, the final outcome of design is as Figure 27. The burst-out effect was added to the design is tent to draw the attention of audience.

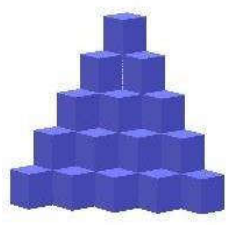

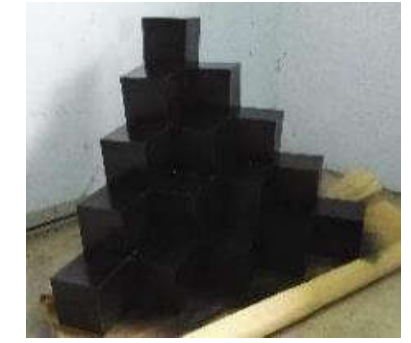

Figure 26. Structure of third artwork.

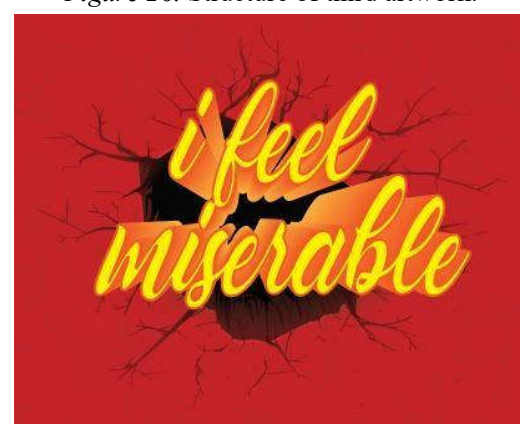

Figure 26. Typography

Design for I feel miserable (2018).

The process continues with analysing of design artwork into structure through anamorphic optical illusion. The calculation of size measurement and perspective angle according to formula and rule of Anamorphic illusion. After the calculation, the design was resized and edited in Adobe Photoshop according the calculation result. The design was executed in print using the material of sticker and stick on the structure. In concordance with the previous art works, this installation requires the audience to view with an exact angulation, in order to view the actual message. Viewing from a different perspective angle will result in partial distortion of the message as shown in Figure 28. Hence Anamorphic illusion in such design will utilise the lower corner of building to deliver message in advertisement.

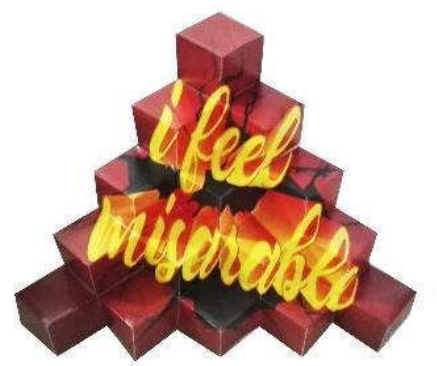

Figure 27. Picture of Second Artwork: I'm Fine; Save Me (2018)
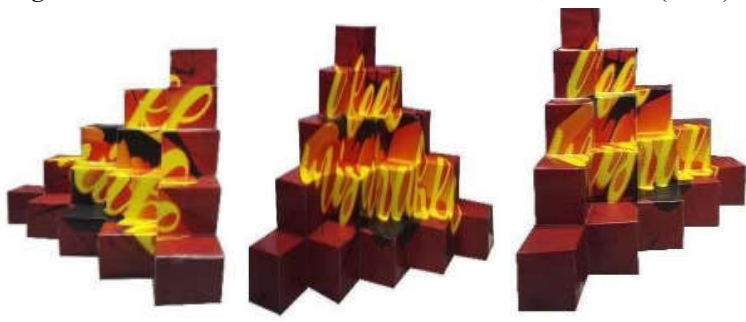

Figure 28. Pictures of different angle for I'm Fine; Save Me (2018). 


\section{CONCLUSION}

Print advertisement is a mean of message communication about products, services or ideas which intended to inform or influence people who received the message and it is usually persuasive by nature and paid by identified sponsors (Bovee, 1992). Signage is generally defined as graphic and symbols intended to communicate information and message to audience, usually as mean of giving direction, purpose of marketing and warning ("What is signage and what is its purpose?", 2017). These two modes of message communication are very familiar and common to the audience. Consequently, cause a risk for them to ignore or forget the message easily. Through the combination Anamorphic illusion in visual message, it increases the attention of audience, in hoping to retain information longer in their mind.

Furthermore, the placement of visual message included advertisement and signage were often constraint by the space and the structure of location. This restriction will influence the effectiveness of message communication due to obstacle of building structure. Through the creative use of Anamorphic illusion, it overcome the constraint of the structure and transform this obstacle to creative eye-catching aids of message to the audience. Anamorphic optical illusion provides a creative way to deliver message to the audience. It allows more variety and interactive approach of displaying message to audience without using CGI. This can be a new innovation of visual language as mean of communication in industry instead of just apply in fine art that only hangs on museum and gallery.

\section{REFERENCES}

[1] Bohn, R., \& Short, J. (2012). Measuring Consumer Information. International Journal of Communication, 6 , 980- 1000. Retrieved from http://ijoc.org/index.php/ijoc/article/viewFile/1566/743

[2] Bovée, Courtland L \& Arens, William F (1992). Contemporary Advertising ( $4^{\text {th }}$ ed). Irwin, Home Wood, IL [3] Bradford, W. C., (2014). Reaching the Visual Learner: Teaching Property Through Art. Retrieved from https://ssrn.com/abstract $=587201$.

[4] Collins, D. L. (1992). Anamorphosis and the Eccentric Observer: Inverted Perspective and Construction of the Gaze. Leonardo,25(1), 73. doi:10.2307/1575625

[5] Few, S. (2006). Visual Communication Care Design Principles For Displaying Quantitative Information. Retrieved February 20, 2018, from https://www.perceptualedge.com/articles/Whitepapers/Vi sual_Communication.pdf.

[6] Ho, A. G. (2013). Typography Today: Emotion Recognition in Typography. Retrieved March 1, 2018, from http://designcu.jp/iasdr2013/papers/2213-1b.pdf

[7] Jin, K. (1992, January 01). Involvement and Advertisement Size Effects on Information Processing. Retrieved March 2, 2018, from http://acrwebsite.org/volumes/7386/volumes/v19/NA-19

[8] Kanyakumari, D. (2017, April 02). Depression: 40\% of Malaysians will suffer from mental health issues in their lifetime. Retrieved February 25, 2018, from https://www.thestar.com.my/news/nation/2017/04/02/mal aysians-will-suffer-from-mental-health-issues-in-theirlifetime/

[9] Kellner, D., \& Share, J. (2007). Critical media literacy, democracy, and the reconstruction of education. In D. Macedo \& S. R. Steinberg (Eds.), Media literacy: A reader (pp. 3-23). New York, NY: Peter Lang.

[10]Kohok, R. (2018, May 20). Why Visual Communication is So Important in Content Marketing. Retrieved June 20, 2018, from https://blog.markgrowth.com/why-visualcommunication-is-so-important-in-contentmarketingd $955 \mathrm{ccd} 932 \mathrm{a} 2$

[11]Lee, K. (2014). 9 Informative Infographics To Guide Your Visual Content Marketing. Retrieved March 7, 2018, from https://blog.bufferapp.com/infographics-visualcontentmarketing

[12]Najafi, F., \& Abbas, M. (2014). A Study of the Semiotic Understanding of Land Art. Asian Social Science, 10. doi:10.5539/ass.v10n17p170

[13]Nakilcioğlu, İ H. (2013). The Effects Of Font Type Choosing On Visual Perception And Visual Communication. Online Journal of Art and Design, 1(3). Retrieved February 5, 2018.

[14] Newman, D. (2016). Research Shows Millennials Don't Respond To Ads. Retrieved January 12, 2018, from https://www.forbes.com/sites/danielnewman/2015/04/28/r ese arch-shows-millennials-dont-respond-toads/\#441a5a9b5dcb

[15] Seckel, A. (2006). The Ultimate book of optical illusions. Sterling Publishing Co.

[16] Siddiqui, K. A., Tarani, S. S., Fatani, S. A., Raza, A., Butt, R. M., \& Azeema, N. (2016). Effect of Size, Location and Content of Billboards on Brand Awareness. Jornal of Business Stidies Quarterly, 8(2), 40-57. Retrieved 13 March, 2018, from http://jbsq.org/wpcontent/uploads/2016/12/December_2016_4.pdf

[17] Timmis, M. A., Bijl, H., Turner, K., Basevitch, I., Taylor, M. J., \& Paridon, K. N. (2017). The impact of mobile phone use on where we look and how we walk when negotiating floor based obstacles. Plos One,12(6). doi:10.1371/journal.pone.0179802

[18] Trafton, A. (2014, December 18). Newest computer neural networks can identify visual objects as well as the primate brain. Retrieved February 20, 2018, from

https://phys.org/news/2014-12-neural-networksvisualprimate-brain.html

[19] What is signage and what is its purpose? (2017). Retrieved January 12, 2018, from http://octink.com/what-issignageand-what-is-its-purpose/ 